Edited by Amy Longshore, Group IS-11

An Affirmative Action/Equal Opportunity Employer

This report was prepared as an account of urork sponsored by an agency of the

United States Government. Neither the United States Government nor any agency thereof, nor any of their employees, makes any uarranty, express or implied, or assumes any legal liability or responsibility for the accuracy, completeness, or usefulness of any information, apparatus, product, or process disclosed, or represents that its use would not infringe prizately owned rights. Reference herein to any specific commercial product, process, or service by trade name, trademark, manufacturer, or otherwise, does not necessarily constilute or imply its endorsement, recommendation, or favoring by the United States Government or any agency thereof. The vieus and opinions of authors expressed herein do not necessarily state or reflect those of the United States Government or any agency thereof. 
LA- -11928-MS

DE91 006613

Preliminary Evaluation of the Electrapette

for Possible Use in the Glovebox

for Pipetting Plutonium Solutions

Elizabeth Hansbury

Bart Ortiz

Charles Roybal 


\title{
PRELIMINARY EVALUATION OF THE ELECTRAPETTE FOR POSSIBLE USE IN THE GLOVEBOX FOR PIPETTING PLUTONIUM SOLUTIUNS
}

\author{
by
}

Elizabeth Hansbury, Bart Ortiz, and Charles Roybal

\begin{abstract}
At the Los Alamos National Laboratory Plutonium Facility, Solution Assay Instruments (SAls) are used to provide real-time information on the plutonium (Pu) content of the process stream at various stages in the process. These analyses are accurate enough to determine, in a relatively short time, information about the efficiency of the preceding step, and therefore the conditions required for the next step.

Among the factors that affect the accuracy of the SAl analysis are techniques used for sampling and for measuring the volume and weight of the sample. Quality Assurance requirenents dictate that conditions that affect measurement reliability be eliminated or reduced to a minimum. Radiation safety dictates that the operations be carried out as quickly as possible to keep radiation exposure to the technician as low as reasonably achievable.

However, these conditions are difficult to achieve while working in heavy glovebox gloves and viewing the work area through leaded-glass windows.

An electronic solution-volume measuring device called an Electrapette was ordered from Matrix Technologies Corporation. It is said to be highly accurate, simple to use, and can handle the $25 \mathrm{ml}$ of solution required for $S A I$ analyses. It is microprocessorcontrolled and comes in two components connected by a detachable cable so that the electronic part can be installed outside the box, whils the nosepiece is inside. The two pieces are connected through a plug-in on the glovebox wall.
\end{abstract}


The Electrapette was tested in three sets of experiments. In the first "cold" lab set, three liquids having diiferent viscosity, density, etc. were tested. Twenty-five-ml aliquots of water were pipetted into each of six tared SAI vials. Twenty-five-ml aliquots of $7 \mathrm{M} \mathrm{HNO}$ were pipetted into another set of six tared SAI vials and the procedure was repeated for $4 \mathrm{M} \mathrm{HCl}$. The vials in each set were weighed separately and the error and reproducibility were calculated. The percent relative standard deviation (RSD) was $0.39,0.1$, and 0.02 , respectively. The error for all three was $2 \%$.

The second set of experiments was run in a hood in Building 4 at the Plutonium Facility (PF-4) and consisted of a computer-assisted analytical balance that corrected for temperature and atmospheric pressure and calculated the mean volume of the water. The error in these experiments ranged from $0.12 \%$ to $0.84 \%$.

The third set of experiments was run in a glovebox using a process solution whose density was determined first. then the solution was pipetted by Electrapette into six tared SAI vials and weighed. The percent RSD of the weighed samples was 0.34 and the percent error was 0.32 . After they were weighed, the six samples were counted in an SAI and the percent RSD of the counting data was 0.91 . The accuracy could not be determined (by using values from a separate Analytical Chemistry Group (CLS-1) analysis) because the samples had been mixed with other feed before being sent to CLS-1 for analysis.

\section{INTRODUCTION}

In plutonium recovery operations at the TA-55 Plutonium Facility of Los Alamos National Laboratory, analyses of the plutonium ( $\mathrm{Pu}$ ) content of process solutions are rrecessary before further processing can be started. Precise analyses are carried out for us by the Analytical Chemistry Group (CLS-1), but these can require several days. So that the processing can continue without delay, samples having $\mathrm{Pu}$ concentrations higher than 2-3 $\mathrm{g} / \mathrm{l}$ are analyzed in a Solution Assay Instrument (SAI) located in a nearby 
dropbox. The results from these analyses provide real-time $\mathrm{Pu}$ accountability as well as information on the efficiency of the chemical reaction just performed.

Because of the difficulty associated with doing precise analytical procedures in the glovebox while wearing heavy gloves, a mothod was needed for obtaining accurately measured samples for counting in the SAI with a minimum of human manipulation.

In a Los Alamos manuscript on SAl measurements by Aaron Goldman, 1 the author stated that the sources of error in SAl analyses from process measurements include sampling technique, sample homogeneity, and weighing or volumetric errors.

From Quality Assurance and Accountability standpoints, factors of concern include human variation in technique from one individual to another, and variation in reproducibility (even by the same individual) because of fatigue, haste, illness, and distractions.

Even more important is the need for a technique that will reduce the time spent carrying out the analysis and thus reduce radioactivity exposure to the individual running it.

A microprocessor-controlled pipettor called an Electrapette, which is made by Matrix Technologies Corporation, was purchased to evaluate its suitability for use in Building 4 of the Plutonium Facility (PF-4). The advertised ${ }^{2}$ advantages are 1) simplicity and ease of operation (depress the trigger to fill the pipette with the preprogrammed volume of liquid, then depress it again to dispense it); 2) accuracy (once it has been calibrated for the type of pipette being used with it and the concentration of the solutions to be pipetted), the pipetting is controlled by microcomputer and no human technique is involved; 3) almest any pipette or even tubing can be used (the accuracy of the glass or plastic pipette inserted in the nosepiece is irrelevant because the programmed Electrapette determines the proper volume); and 4) the nosepiece is replaceable. The Electrapette can be physically separated into its 
electronic component, which can be installed outside the dropbox, and the nosepiece, which can be installed inside the box and connected by cable through a plug-in on the wall of the glovebox. The nosepiece holds the pipette being used and also contains a filter and the trigger control. If the nosepiece becomes corroded by nitric acid fumes, it can be replaced separately (and more cheaply) than the electronic component. A major advantage from a health and safety standpoint is the reduction in exposure time to the technician while transferring sample into the SAI vial.

The unadvertised disadvantages might include 1) the nosepiece being too easily affected by the corrosive atmosphere in the box; 2) the microprocessor keyboard outside the box being inadvertently, maliciously, or accidentally altered so that the calibration setting would be changed unknown to the operator; and 3) the accuracy and precision not holding up over prolonged use.

\section{EXPERIMENTAL}

\section{A. Cold Lab Experiments}

The first three experiments with the Electrapette were carried out in a "cold" (containing no radioactive materials) laboratory using liquids having known densities: water, $7 \underline{M}$ nitric acid $\left(\mathrm{HNO}_{3}\right)$, and $4 \underline{\mathrm{M}}$ hydrochloric acid $(\mathrm{HCl})$. In each experiment, six labeled, empty vials with their caps were tared on a calibrated analytical balance. Using the Electrapette and a $25-\mathrm{ml}$ disposable "shortie" glass pipette, $25 \mathrm{ml}$ of the liquid to be weighed was pipetted into each vial. Then each vial, including the cap and liquid, was weighed and the tare subtracted to obtain the weight of each of the six samples. Surgical gloves were worn when handling the vials. The balance was a Mettler AE-100. Corning 25-ml "shortie" disposable glass serological pipettes were chosen because their shorter length would be easier to handle with the Electrapette in the glovebox.

Calculation of accuracy and reproducibility: The weights of six $25-\mathrm{ml}$ aliquots of deionized water, $7 \underline{M} \mathrm{HNO}_{3}$, and $4 \underline{\mathrm{M} \mathrm{HCl}}$ were obtained by the method described above. Then the average of the six weights for each solution was determined, followed by the deviation from the mean 
(average), the relative standard deviation (RSD), and the percent error. See Table 1. for the results.

\begin{tabular}{lcccc}
\hline \hline \multicolumn{5}{l}{ Table 1. Electrapette Studies in "Cold" Lab. } \\
\hline $\begin{array}{c}\text { Mean } \\
\text { Weight (g) }\end{array}$ & $\begin{array}{c}\text { Standard } \\
\text { Deviation }\end{array}$ \\
Sample & g) & \% RSD & \% Error \\
\hline $\mathrm{H}_{2} \mathrm{O}$ & 25.5 & 0.1 & 0.39 & 2 \\
$7 \underline{\mathrm{M}} \mathrm{HNO}_{3}$ & 31.08 & 0.03 & 0.1 & 2 \\
$4 \underline{\mathrm{M}} \mathrm{HCl}$ & 27.26 & 0.44 & 0.02 & 2 \\
\hline \hline
\end{tabular}

Cenclusion: The results of the "cold" experiments were encouraging enough to continue the study in PF-4 under conditions approximating t'iose found in the glovebox.

\section{B. Computer-Assisted Analytical Balance Experiments}

The experiment was then moved into PF-4 to a hood in Room 128 to repeat the water experiments using CLS-1 equipment and advice. The balance is computer-interfaced and corrects for temperature and barometric pressure. The capacity of the balance is limited so we could not use $25-\mathrm{ml}$ vials and caps. It is programmed for 4,10 , etc. repetitive weighings. Since 10 aliquots of $25 \mathrm{ml}$ each would have overloaded the balance, we settled on two experiments of 4 pipettings each into a $250-\mathrm{ml}$ plastic beaker. Two technicians did the pipetting, each taking a set of four. A new disposable $25-\mathrm{ml}$ "shortie" pipette was used with the Electrapette each time.

Although the volume entered into the balance computer was off by a factor of $10(2.500 \mu \mathrm{l}$ instead of $25000 \mu \mathrm{l})$, excellent results were obtained by recalculating using the correct entry for volume and the corrected weights given by the balance and using two different methods for calculating. One method was a manual calculation; the other used a calculator program. For Set 1 the barometris pressure was $584 \mathrm{~mm}$ and the temperature was $20.8^{\circ} \mathrm{C}$. For Set 2 the barometric pressure was $584 \mathrm{~mm}$ and the temperature was $21.2^{\circ} \mathrm{C}$. See Tables 2 and 3 for the results. 
Table 2. Reproducibility of the Weights of Electrapetted Water Samples on a Computer-Interfaced Balance.

\begin{tabular}{ccc}
\hline $\begin{array}{c}\text { Electrapetted } \\
\text { Sample }\end{array}$ & $\begin{array}{c}\text { Set 1 } \\
(\mathbf{m g})\end{array}$ & $\begin{array}{c}\text { Sot 2 } \\
(\mathbf{m g})\end{array}$ \\
\hline 1 & 24914.5 & 24789.2 \\
2 & 25116.6 & 24856.4 \\
3 & 24901.4 & 24822.1 \\
4 & 24906.9 & 24694.8 \\
\hline Miean Weight & 24959.85 & 24790.63 \\
\hline \hline
\end{tabular}

Table 3. Computer-Interfaced Balance Experiments.

\begin{tabular}{|c|c|c|c|c|c|c|c|c|c|}
\hline & & \multirow{2}{*}{$\begin{array}{c}\text { Mean } \\
\text { Weight } \\
\text { (mg) }\end{array}$} & \multirow{2}{*}{$\begin{array}{c}\text { Mean } \\
\text { Volume } \\
(\mu l) \\
\end{array}$} & \multicolumn{2}{|c|}{$\begin{array}{c}\text { Standard } \\
\text { Deviation } \\
\text { by }\end{array}$} & \multicolumn{2}{|c|}{$\begin{array}{l}\% \text { RSD } \\
\text { by }\end{array}$} & \multicolumn{2}{|c|}{$\begin{array}{l}\% \text { Error } \\
\text { by }\end{array}$} \\
\hline . & & & & $\begin{array}{l}\mathrm{Wt} \\
(\mathrm{mg})\end{array}$ & $\begin{array}{l}\text { Vol } \\
(\mu l) \\
\end{array}$ & $\begin{array}{l}\mathrm{Wt} \\
(\mathrm{mg})\end{array}$ & $\begin{array}{l}\text { Vol } \\
(\mu 1)\end{array}$ & $\begin{array}{l}\mathrm{Wt} \\
(\mathrm{mg})\end{array}$ & $\begin{array}{l}\text { Vol } \\
(\mu 1)\end{array}$ \\
\hline Set 1 & $\begin{array}{l}\text { Manual Calculation } \\
\text { Calculator Program }\end{array}$ & 24959.85 & 25029.6 & $\begin{array}{r}90.62 \\
10463\end{array}$ & 14.8 & 0.36 & 0.06 & 0.16 & 0.12 \\
\hline Set 2 & $\begin{array}{l}\text { Manual Calculation } \\
\text { Calculator Program }\end{array}$ & 24790.63 & 24862.3 & $\begin{array}{l}60.21 \\
69.53\end{array}$ & 68.85 & $\begin{array}{l}0.24 \\
0.28\end{array}$ & 0.28 & $\begin{array}{l}0.84 \\
0.84\end{array}$ & $\begin{array}{l}0.55 \\
0.55\end{array}$ \\
\hline
\end{tabular}

Conclusion: The pipetting error using the certified and computer-. interfaced balance was even lower than the $2 \%$ error found in the earlier experiments.

\section{Experiment with a Plutonium-Containing Process Solution}

Original plans for this stage had called for pipetting plutonium standards that are used for calibrating the SAI instruments, then counting the samples in each SAI in use at the time. The Pu standards consist of several known concentrations of $\mathrm{Pu}$ in $\mathrm{HNO}_{3}$ prepared by CLS-1 and are stored in volumetric flasks. However, the necks of the volumetric flasks were too narrow to admit the wide-diameter "shortie" pipettes. Also, if the number of counts (SAl analyses on 103,104, 105, and 107) for each concentration (for statistical purposes) had been carried out as planned for each SAI, the instruments would have been tied up for a considerable time. Therefore, the plan to use Pu standards was abandoned. 
The Electrapette was moved into Room 420 for testing in a glovebox environment using an authentic process solution in nitric acid. To obtain the authentic density of the feed solution, we weighed $25 \mathrm{ml}$ of the sparged solution in a tared $25-\mathrm{ml}$ volumetric flask. The weight of the $25 \mathrm{ml}$ in the flask was the standard weight that the Electrapette should deliver to each SAI vial.

Procedure for testing the Electrapette using a Pu-containing process solutious

a) A tare weight was obtained on a $25-\mathrm{ml}$ volumetric flask and cap.

b) Tare weights were obtained on six SAl counting vials with caps.

c) Several 25-ml Corning "shortie". disposable glass pipets were introduced into the box through the pencil port.

d) Feed solution was sparged for 12 minutes before a portion was drawn into a $250-\mathrm{ml}$ beaker. From this solution the $25-\mathrm{ml}$ tared volumetric flask was filled nearly to the line-the last part brought to the line using a soft plastic pipette. The flask was then capped and weighed.

e) Using the Electrapette and a new "shortie" disposable pipette each time, six 25-ml samples of the feed were transferred into the six tared SAl vials. The vials were capped for weighing and counting.

f) The volumetric flask and the six SAl vials were weighed on balance B05 and the SAI samples were counted in SAI 103, using the volumetric method (see NMT-2 SOP 413-GEN). Simple statistical procedures were used to calculate reproducibility and accuracy data for this experiment as well as for the earlier "cold" experiments.

We carried out the calculations for precision and accuracy using one definition for standard deviation: "The square root of the arithmetic average of the squares of the deviations from the mean." Table 4 shows the precision and accuracy calculations for the weights of the Electrapetted feed solutions. 
Table 4. Precision and Accuracy of Six Electrapetted 25-ml Feed Solutions ${ }^{a}\left(\mathrm{~B} 05^{b}\right)$

\begin{tabular}{ccccc}
\hline $\begin{array}{c}\text { SAI } \\
\text { Vial }\end{array}$ & $\begin{array}{c}\text { Weight } \\
\text { Sample }(\mathrm{g})\end{array}$ & $\begin{array}{c}\text { Mean } \\
\text { Weight }\end{array}$ & Deviation & (Deviation) \\
\hline $\mathrm{A}-1$ & 34.4 & 34.3 & 0.1 & 0.01 \\
$\mathrm{~A}-2$ & 34.5 & 34.3 & 0.2 & 0.04 \\
$\mathrm{~A}-3$ & 34.4 & 34.3 & 0.1 & 0.01 \\
$\mathrm{~A}-4$ & 34.2 & 34.3 & 0.1 & 0.01 \\
$\mathrm{~A}-5$ & 34.3 & 34.3 & 0 & 0 \\
$\mathrm{~A}-6$ & 34.2 & 34.3 & 0.1 & $\underline{0.01}$ \\
Total & 206.0 & & & 0.08
\end{tabular}

Mean Weight $=\frac{2060}{5}=34.3 \mathrm{~g} \quad$ Mean $(\text { Deviation })^{2}=\frac{0008}{5}=0.0133$

Standard Deviation $=\sqrt{0.0133}=0.1153$

$\% \operatorname{RSD}=\frac{0.1153}{34.3}=0.6034=0.34$

Arithmetic Average $=34.3 \pm 0.12 \mathrm{~g}$

known Weight $=34.41 \mathrm{~g}$

-Observed Weight $=34.3 \mathrm{~g}$

Difference $\quad=0.11 \mathrm{~g}$

$\%$ Error $=\frac{0.11}{34.41}=0.0032=0.32$

${ }^{\mathrm{a}} \mathrm{Standard}$ weight of $25 \mathrm{ml}$ of fecd solution in the volumetrir flask cquals $34.11 \mathrm{~h}$. ${ }^{6}$ Based on data from balance B05.

Table 5 shows the data on the same six samples as given by SAI 103 using the volume method. The results are given as the plutenium centent calculated back to the original feed $(13.5 \mathrm{l})$, not the plutonium content of each vial. The reproducibility and deviation from the mean can be calculated, but not the percent error because a CLS-1 Pu assay for ED $37 \mathrm{~K}$ is unavailable.

The larger deviation and RSD in the counting statistics probably is because the data is based on the larger volume of the original feed. Even so, the RSD is less than $1 \%$. 
Table 5. Precision of Pu Solution Electrapetted Six Times and Counted in SAI I03.

\begin{tabular}{ccccc}
\hline $\begin{array}{l}\text { Vial } \\
\text { Number }\end{array}$ & $\begin{array}{c}\text { Weight } \\
\text { Pu }(\mathrm{g})\end{array}$ & $\begin{array}{c}\text { Mean } \\
\text { Weight }\end{array}$ & $\begin{array}{ccc}\text { Deviation } \\
\text { (Deviation) }\end{array}$ \\
\hline A-1 & 413.7 & 412.8 & 0.9 & 0.81 \\
A-2 & 416.2 & 412.8 & 3.4 & 11.56 \\
A-3 & 412.2 & 412.8 & 0.6 & 0.36 \\
A-4 & 406.7 & 412.8 & 6.1 & 37.21 \\
A-5 & 41.8 .0 & 412.8 & 5.2 & 27.04 \\
A-6 & 410.0 & 412.8 & 2.8 & 7.81 \\
Total & 2476.8 & & & 84.82
\end{tabular}

Mean Weight $=\frac{2476.8}{6}=412.8 \mathrm{~g} \quad$ Mean $(\text { Deviation })^{2}=\frac{84.82}{6}=14.14$

Standard Deviation $=\sqrt{14.14}=3.76$

Arithmetic Average Woight of $P_{11}=412.8 \pm 3.8 \mathrm{~g}$

$\%$ RSD $=\frac{3.76}{112.8}=0.0091=0.91$

Cenclusion: These preliminary studies show that in the short term and in capable hands, the Electrapette gives very reproducible results that shouldn't be influenced by extraneous personal factors such as technique or level of skill. A longer trial period with a variety of technicians testing it will tell us whether it is easy to learn and use, how well it withstands the glovebox environment, and whether it maintains its precision and accuracy over the long term.

\section{ACKNOWLEDGMENTS}

We would like to thank Margaret Romero Trujillo, Craig Taylor, and Donald Vance from CLS-1 at TA-55 for the use of their computerinterfaced electronic analytical balance and for their help and suggestions. We appreciate the help of Bennie Gomez (NMT-2) who arranged for obtaining the plug-ins, having them wired for the Electrapette, and installing one in a glovebox. We thank Charles Bonner (NMT-4) for his input regarding plutonium standards. Finally we thank Steve Yarbro, Jim Dyke, and Tim Hayes from NMT-2 for their valuable input. 


\section{REFERENCES}

1. A. S. Goldman, "An Assessment of the Measurement Control Program for Solution Assay Instruments at the Los Alamos National Laboratory Plutonium Facility," Los Alamos National Laboratory report LA-10373-MS, May 1985.

2. G. P. Kalmakis," A Microprocessor-Controlled Hand-Held Pipettor," American Laboratory (October 1987), pp.128-132. 

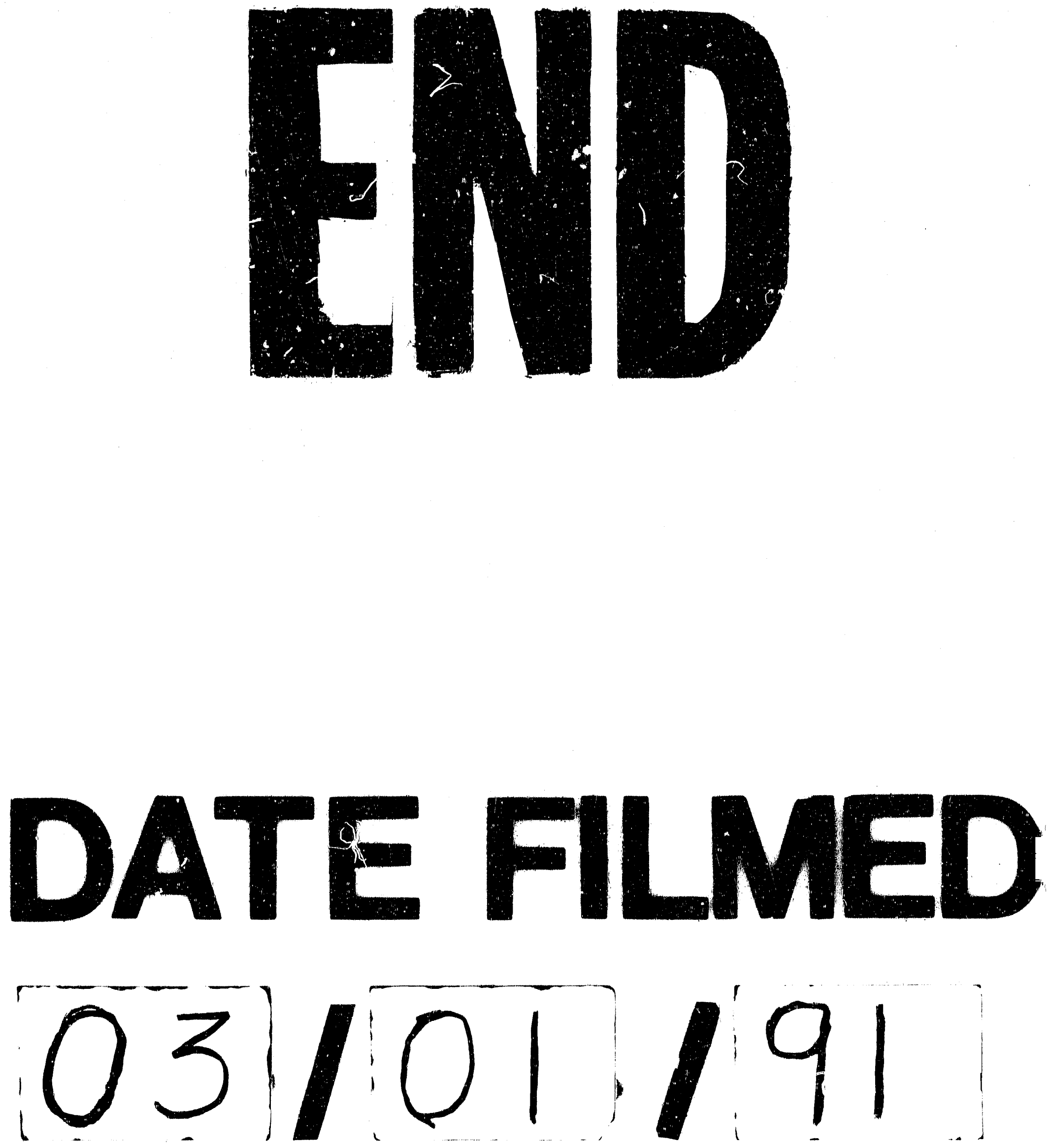
